\title{
HUBUNGAN PERAN SERTA KADER POSYANDU DENGAN PERAWATAN HIPERTENSI PADA LANJUT USIA (LANSIA) DI DESA SALAMREJO SENTOLO KULON PROGO
}

\author{
Sugiyanto $^{1}$ \\ ${ }^{1}$ Universitas 'Aisyiyah Yogyakarta, Jalan Ring Road Barat No. 63, Nogotirto, Gamping, Sleman, Daerah \\ Istimewa Yogyakarta, Email: sugiantokotagede@gmail.com
}

\begin{abstract}
Background: One of the most prevalent cardiovascular problems in elderly people is hypertension. Health cadres are those who voluntarily dedicate their time to have concern about elderly people's health status in the community. Health cadres' roles are important to promote elderly people quality of life, including their hypertension management.

Objectives: This research aimed to analyzethe correlation between the role of health cadres of elderly posyandu and the treatment of hypertension at Salamrejo Village Sentolo Kulon Progo.

Methods:This research was a correlational study with a cross sectional approach. The sample of this study was selectedwith a total sampling technique, drawn 57 hypertension patients. Data were analyzedwith Spearman rank correlation.

Results:The result showed that coefficient correlation value of Spearman's rho $(r)$ between the role of cadres of elderly posyandu and the treatment of hypertension patients was 0.294 and $p$-value was $0.026(p<$ 0.05).

Conclusion:It can be concluded that there was a positive and significant correlation between the role of cadres of elderly posyandu and the treatment of hypertension.
\end{abstract}

Key word:cadres, elderly posyandu, hypertension

\section{PENDAHULUAN}

Keberhasilan pembangunan di bidang kesehatan telah membuahkan hasil meningkatnya umur harapan hidup usia lanjut yang mengakibatkan meningkatnya jumlah dan proporsi penduduk lansia. Di Asia Tenggara tahun 2011 jumlah lansia usia > 60 tahun sebesar 142 juta jiwa. Indonesia secara demografi berdasarkan sensus penduduk lansia selalu meningkat, sehingga Indonesia termasuk negara yang memasuki era penduduk berstruktur lansia (aging structured population) karena jumlah penduduk yang berusia 60 tahun ke atas sebesar 14,4 juta atau $(7,18 \%)$ dari total penduduk. Jumlah penduduk lansia di Indonesia pada tahun 2006 sebesar kurang lebih 19 juta, dengan usia harapan hidup 66,2 tahun. Pada tahun 2010 mengalami peningkatan menjadi 23.992 .553 jiwa $(9,77 \%)$ dengan usia harapan hidup 65 tahun, sementara pada tahun 2011 jumlah lansia sebesar 24 juta jiwa (9,51\%), dengan usia harapan hidup 67,4 tahun. $^{(1)}$ Menurut Rencana Pembangunan Jangka Menengah Nasional Kemenkes tahun 2014 (2) menunjukan bahwa Indonesia memiliki umur harapan hidup penduduk rata-rata 72 tahun. Dan pada tahun 2020 diperkirakan akan meningkat menjadi 28,8 juta atau $11,34 \%$ dari total penduduk. Dengan peningkatan jumlah lansia akan menimbulkan dampak yang komplek bagi lansia yaitu masalah penyakit degeneratif yang sering 
menyertainya, bersifat kronis dan multi patologis, terutama sistem kardiovaskular.

Salah satu gangguan sistem kardiovaskular pada lansia terbanyak adalah hipertensi. Gangguan penyakit ini harus dikelola dengan baik, karena memiliki banyak komplikasi, bahkan dapat menyebabkan kematian mendadak. Word Health Organization (WHO) tahun 2011 mencatat angka kejadian hipertensi sekitar satu miliar penderita, dengan jumlah kematian tiap tahunnya sekitar 9,4 juta warga dunia. Sedangkan wilayah Asia Tenggara sebanyak 156.273 jiwa dengan tingkat kematian 14,70\% per 100.000 penduduk. Di Indonesia prevalensi hipertensi mencapai $31,7 \%$ dari populasi pada usia 18 tahun ke atas. Angka kematian hipertensi mencapai $6.8 \%$, setelah stroke $(15,4 \%)$ dan tuberkulosis $(7,5 \%)$ tiap tahunnya. ${ }^{(3)}$

\section{Prevalensi penyakit hipertensi} berdasarkan survey penyakit tidak menular pada tahun 2009 di Yogyakarta, hipertensi merupakan penyakit yang menempati urutan pertama dengan jumlah kasus sebesar 7.064 $(39,41 \%)$ kasus dari seluruh penyakit. ${ }^{(3)}$ Berdasarkan IHIS ( Integrated Health of Information System ) dan sasaran SPM tahun 2013 Dinas Kesehatan Kabupaten Kulon Progo jumlah lansia dengan hipertensi sebesar 8.781 dari 81.914 lansia. Kecamatan Sentolo terdapat kurang lebih 1.435 kasus dari 9.134 lansia. Dinas Kesehatan Kulon Progo Tahun $2013^{(4)}$
Kader merupakan orang yang terpilih, bekerja secara sukarela, sabar dan memahami lansia. Dalam melaksanakan perannya, kader sering sekali mempunyai hambatan pada jumlah dan keaktifan kader. Pendekatan, pembinaan, dan pelatihan kader posyandu lansia harus selalu diadakan melalui pertemuan oleh institusi terkait, misalnya puskesmas, LSM, atau kerohaniawan.

Sehubungan uraian tersebut, peran serta kader terhadap pemeliharaan lansia hipertensi terutama dalam hal peningkatan kesehatan dan penggerak perilaku hidup sehat di Desa Salamrejo sangat diperlukan, agar tidak terjadi tingkat keparahan dan risiko hipertensi pada lansia, sehingga akan tercapai masa tua yang sehat, bahagia, berdaya guna dan produktif selama mungkin. Dari beberapa penjelasan sebelumnya, peneliti tertarik meneliti tentang hubungan peran serta kader posyandu dengan perawatan hipertensi pada lansia di Desa Salamrejo, Sentolo, Kulon Progo

\section{BAHAN DAN CARA PENELITIAN}

Alat yang digunakan dengan kuesioner dengan pertanyaan tertutup. Metode yang digunakan dalam penelitian ini adalah jenis penelitian Correlational descriptive, yaitu untuk mengetahui ada tidaknya hubungan antara dua variabel. Pendekatan waktu yang digunakan adalah cross-sectional.

Penelitian ini dilaksanakan di Desa Salamrejo, Sentolo, Kulon Progo pada 
tanggal 27 Desember 2014. Sampel pada penelitian ini menggunakan teknik total sampling, dengan 57 penderita hipertensi. Teknik analisis data menggunakan Spearman Rank.

\section{HASIL DAN PEMBAHASAN}

\section{Karaktersitik responden}

Karakteristik responden berdasarkan usia dapat dilihat pada tabel berikut ini :

Tabel 1 Karakteristik Responden Berdasarkan Usia

\begin{tabular}{|c|c|c|}
\hline Usia & Frekuensi & $\%$ \\
\hline 56 - 59 tahun & 28 & 49,12 \\
\hline $60-69$ tahun & 16 & 28,07 \\
\hline$\geq 70$ tahun & 13 & 22,81 \\
\hline Total & 57 & 100,0 \\
\hline
\end{tabular}
responden paling banyak kelompok pada umur lansia awal yaitu antara 56 - 59 tahun sebanyak 28 lansia $(49,12 \%)$, sedangkan paling sedikit kelompok umur lansia risiko tinggi yaitu $\geq 70$ tahun $(22,81 \%)$.

Karakteristik responden berdasarkan lansia yang masih bekerja /tidak bekerja dapat dilihat pada tabel berikut ini :

Tabel 2 Karakteristik Responden Masih Bekerja

\begin{tabular}{ccc}
\hline $\begin{array}{c}\text { Lansia } \\
\text { Bekerja/Tdk } \\
\text { bekerja }\end{array}$ & Frekuensi & $\%$ \\
\hline $\begin{array}{c}\text { Lansia msh } \\
\text { bekerja } \\
\text { Lansia tdk } \\
\text { bekerja }\end{array}$ & 59 & 86 \\
\hline Total & $\mathbf{5 7}$ & 14 \\
\hline
\end{tabular}

Dari tabel di atas, karakteristik responden pekerjaan paling banyak sebagai petani sebanyak 28 orang $(49,1 \%)$, sedangkan paling sedikit bekerja sebagai IRT sebanyak 8 orang (14\%). Karakteristik responden berdasarkan pendidikan dapat dilihat pada tabel berikut ini:

\begin{tabular}{ccc}
\multicolumn{3}{c}{ Tabel 3 Karakteristik Responden } \\
Pendidikan \\
\hline Pendidikan & Frekuensi & $\%$ \\
\hline SD & 28 & 49.1 \\
SMP & 15 & 26.3 \\
SMA & 12 & 21.1 \\
PT & 2 & 3.5 \\
Total & $\mathbf{5 7}$ & $\mathbf{1 0 0 . 0}$ \\
\hline
\end{tabular}

Dari tabel di atas, karakteristik responden berdasarkan pendidikan paling banyak berpendidikan sekolah dasar sebanyak 28 orang $(49,1 \%)$, sedangkan paling sedikit berpendidikan perguruan tinggi sebanyak 2 orang (3,5\%).

Karakteristik responden berdasarkan lama sakit dapat dilihat pada tabel berikut ini: Tabel 4 Karakteristik Responden Berdasarkan Lama Sakit

\begin{tabular}{ccc}
\hline Lama sakit & Frekuensi & $\%$ \\
\hline 2 th & 2 & 3.5 \\
3 th & 6 & 10.5 \\
4 th & 25 & 43.9 \\
5 th & 15 & 26.3 \\
6 th & 7 & 12.3 \\
7 th & 1 & 1.8 \\
9 th & 1 & 1.8 \\
Total & $\mathbf{5 7}$ & $\mathbf{1 0 0 . 0}$ \\
\hline
\end{tabular}

Dari tabel di atas didapat karakteristik responden berdasarkan lama sakit paling banyak lama sakit adalah 4 tahun, sebanyak 25 orang $(43,9 \%)$, sedangkan paling sedikit lama sakitnya adalah 7 dan 9 tahun, masingmasing sebanyak 1 orang $(1,8 \%)$. 
Peran serta kader posyandu di Desa Salamrejo, Sentolo, Kulon Progo.

Hasil penelitian pada peran serta kader posyandu lansia dapat dilihat di tabel berikut ini:

Tabel 5 Peran Serta Kader Posyandu Lansia

\begin{tabular}{ccc}
\hline $\begin{array}{c}\text { Peran serta kader } \\
\text { posyandu lansia }\end{array}$ & Frekuensi & $\%$ \\
\hline Tinggi & 43 & 75.4 \\
Sedang & 14 & 24.6 \\
Total & $\mathbf{5 7}$ & $\mathbf{1 0 0 . 0}$ \\
\hline
\end{tabular}

Dari tabel di atas dapat dilihat bahwa hasil penelitian tentang peran serta kader posyandu lansia di Desa Salamrejo.Sentolo, Kulon Progo paling banyak pada kategori tinggi sebanyak 43 orang (75,4\%), sedangkan paling sedikit pada kategori sedang sebanyak 14 orang (24,6\%).

Hasil penelitian dinyatakan baik, dilihat dari aspek upaya peningkatan kesehatan, kader sudah sebagian berhasil mengajak lansia dengan hipertensi untuk datang ke posyandu, kader mampu menjelaskan manfaat posyandu lansia, kader memberitahu jadwal pelaksanaan posyandu sebelum posyandu lansia terlaksana.

Pemberitahuan tempat pelaksanaan posyandu oleh kader dengan cara datang ke rumah penderita hipertensi terutama yang sudah lansia dan membicarakan posyandu lansia. Sekaligus menanyakan kondisi kesehatan lansia dengan hipertensi sebagai bentuk perhatian. Terkadang kader juga memberikan penyuluhan tentang pola makan, manfaat olahraga, pengendalian stres, kepatuhan minum obat bagi penderita hipertensi, dan juga mendengar keluhan yang disampaikan dan dirasakan oleh lansia. Kegiatan lain yang dilakukan kader yaitu menimbang berat badan, mengukur tekanan darah, dan mengukur kadar gula darah dengan pendampingan petugas dari puskesmas, hal ini merupakan bentuk peran serta kader posyandu lansia terhadap upaya kesehatan dalam hal perawatan hipertensi. Hasil penelitian tersebut relevan dengan penelitian yang menyatakan peran dan tugas kader dalam menggerakkan masyarakat, membantu petugas kesehatan, mengelola pertemuan bulanan kader, dan mengelola pelaporan bulanan posyandu yang sudah berjalan dengan baik, yaitu sudah dilakukan sesuai pedoman pelaksanaan posyandu lansia. ${ }^{(5)}$

\section{Perawatan hipertensi pada lansia di Desa Salamrejo, Sentolo, Kulon Progo.}

Hasil penelitian pada perawatan hipertensi pada lansia dapat dilihat ditabel berikut ini:

\begin{tabular}{ccc}
\multicolumn{3}{c}{ Tabel 6 Perawatan Pasien Hipertensi } \\
\hline Kategori & Frekuensi & $\%$ \\
\hline Tinggi & 7 & 12.3 \\
Sedang & 49 & 86 \\
Kurang & 1 & 1.8 \\
Total & $\mathbf{5 7}$ & $\mathbf{1 0 0 . 0}$ \\
\hline
\end{tabular}

Dari tabel di atas dapat dilihat bahwa hasil penelitian tentang perawatan hipertensi pada lansia di Desa Salamrejo, Sentolo, Kulon Progo paling banyak pada kategori sedang sebanyak 49 orang (86 \%), 
sedangkan paling sedikit pada kategori kurang sebanyak 1 orang (1.8\%).

Hasil penelitian menunjukkan bahwa lansia dengan hipertensi masih ada yang tidak patuh walaupun sudah ada kader yang mengingatkan. Dilihat dari karakteristik pendidikan dan pekerjaan para responden mayoritas berpendidikan sekolah dasar dan pekerjaan sebagai petani yang masih produktif, maka hal ini dapat memicu ketidakpatuhan dikarenakan pengetahuan yang kurang dari para responden dan lebih mementingkan pekerjaannya. Sedangkan dilihat dari karakteristik responden berdasarkan lama sakit mayoritas responden paling banyak lama sakitnya 4 tahun, sehingga para responden jenuh dalam mematuhi aturan agar menjaga hipertensi. Hasil penelitian ini relevan dengan hasil penelitian yang meneliti faktor-faktor yang berhubungan dengan hipertensi pada lansia yaitu pendidikan, riwayat keluarga, dan aktivitas fisik menjadi faktor kejadian hipertensi. Hal ini sesuai dengan hasil penelitian menyatakan paling banyak pada kategori sedang sebanyak 49 orang (86\%), Dilihat dari karakteristik pendidikan dan pekerjaan para responden mayoritas berpendidikan sekolah dasar dan bekerja sebagai petani, hal ini dapat memicu ketidakpatuhan dikarenakan pengetahuan yang kurang dari para responden dilihat dari latar belakang pendidikan. ${ }^{(6)}$

\section{Hubungan peran serta kader posyandu lansia dengan perawatan hipertensi pada lansia di Desa Salamrejo, Sentolo, Kulon Progo}

Hasil penelitian dari lembar kuisoner untuk mengetahui hubungan peran serta kader posyandu lansia dengan perawatan hipertensi pada lansia dapat dilihat di tabel berikut ini :

Tabel 7 Correlation Spearman's rho Pada Hubungan Peran Serta Kader Posyandu Lansia Dengan Perawatan Pasien Hipertensi

\begin{tabular}{lc}
\hline \multicolumn{2}{c}{ Correlation Spearman's rho } \\
\hline Correlation Coefficient & 0,294 \\
Sig. (2-tailed) & 0,026
\end{tabular}

Pengujian hipotesis dilakukan dengan menggunakan analisis korelasi Spearman's rho. Analisis ini dipakai untuk mengukur koefisien korelasi antara dua variabel. Analisis ini dimaksudkan untuk mengungkap hubungan antara variabel yang satu dengan variabel yang lainnya. Berdasarkan hasil penelitian ini diperoleh harga koefisien hubungan Spearman's rho (r) antara peran serta kader posyandu lansia dengan perawatan hipertensi pada lansia sebesar 0,294 dan nilai $p$-value sebesar 0,026<0,05. Dari hasil tersebut dapat disimpulkan bahwa ada hubungan yang signifikan antara peran serta kader posyandu lansia dengan perawatan pasien hipertensi.

Hasil penelitian ini diperoleh harga koefisien hubungan Spearman's rho ( $r$ ) antara peran serta kader posyandu lansia dengan perawatan hipertensi pada lansi sebesar 0,294 dan nilai $p$ - value sebesar 
$0,026<0,05$. Dari hasil tersebut dapat disimpulkan bahwa ada hubungan dan signifikan antara peran serta kader posyandu lansia dengan perawatan hipertensi pada lansia. Hal ini sesuai dengan teori ${ }^{(7)}$ bahwa peran serta atau peranan merupakan suatu pola tingkah laku, kepercayaan, nilai, sikap yang diharapkan oleh masyarakat muncul dari seseorang sesuai dengan kedudukannya dalam suatu organisasi yang dapat memberikan manfaat bagi sekelompok orang. Suatu tindakan yang dilakukan sesuai hasil penelitian $^{(8,9)}$, yaitu untuk mengontrol tekanan darah agar tetap dalam batas normal dengan cara mengendalikan faktor-faktor yang dapat menyebabkan tingkat keparahan keadaan hipertensi yaitu pola makan yang tidak baik, kelebihan berat badan, kurangnya aktivitas fisik secara aerobik atau olahraga, kurang istrahat, stres, kebiasaan merokok, konsumsi alkohol, dan dengan cara minum obat antihipertensi secara tidak teratur. Hasil penelitian ini ada sebagian keselarasan dengan penelitian ${ }^{(8)}$ yang menyatakan bahwa ada pengaruh peran keluarga dan peran kader terhadap pemanfaatan pelayanan posyandu lansia. Peran keluarga (peran berdasarkan harapan maysarakat) $P$-Value 0.003, Peran kader (membangkitkan kemauan untuk berubah) $P$-Value 0.000 , sehingga bagi penderita termotivasi untuk dapat merawat diri atau melakukan perawatan ke posyandu lansia.

Kaitannya dengan perawatan hipertensi pada hasil penelitian menunjukkan bahwa terdapat hubungan antara peran serta kader dengan perawatan hipertensi. Hasil sesuai dengan hasil penelitian sebelumnya, bahwa $^{(10)}$ peran serta kader dalam surveilan penyakit dan masalah kesehatan adalah melihat, mendengar, mencatat untuk menemukan gejala dan masalah kesehatan, menemukan, melaporkan, dan melakukan upaya pencegahan dan penanganan sederhana. Dalam pelaksanaan peran menemukan gejala, tanda, serta masalah kesehatan yang ada di masyarakat, informasi diperoleh dari posyandu, laporan dari masyarakat, laporan dasa wisma, kunjungan rumah, kegiatan sosial masyarakat. ${ }^{(11)}$ Hasil penelitian ini menunjukkan bahwa terdapat hubungan peran serta kader yang baik memiliki hubungan positif dengan perawatan hipertensi yang dilakukan oleh para lansia.

\section{KESIMPULAN}

Berdasarkan hasil penelitian dan pembahasan, maka dapat disimpulkan bahwa hubungan peran serta kader posyandu lansia dengan perawatan hipertensi pada lansia di Desa Salamrejo, Sentolo, Kulon Progo di dapat hasil penelitian dengan nilai koefisien Spearman's rho sebesar 0,026 yang menyatakan bahwa terdapat hubungan peran serta kader posyandu lansia dengan perawatan pasien hipertensi, dengan kategori cukup.

Saran bagi responden diharapkan melalui peran serta kader posyandu lansia dapat merawat penyakit hipertensi secara mandiri, 
sehingga akan tercapai masa tua yang sehat, bahagia, berdaya guna dan produktif selama mungkin. Bagi peneliti selanjutnya diharapkan menjadi sumber informasi ke depannya untuk melakukan penelitian tentang analisis efektivitas peran serta kader posyandu lansia dengan perawatan hipertensi.

\section{KEPUSTAKAAN}

1. Dep. Kes Rl., Pedoman Pengobatan Dasar Puskesmas, Din.Kes Propinsi DIY. 2011.

2. Widiyani, Badan Kesehatan Dunia. 2013.

3. Kemenkes RI Pengendalian Penyakit tidak menular di Puskesmas Jakarta. 2012.

4. Dinas Kesehatan Kabupaten Kulon Progo Prevalensi Penyakit Hypertensi Berdasarkan Survey Penyakit Tidak Menular di Yogyakarta. 2013.

5. Dirjen Bina Kesehatan Masyarakat Pelatihan Kader Kesehatan dan Tokoh Masyarakat dalam Pengembangan Desa Siaga. Depkes RI Jakarta. 2007.
6. Zainal Arifin Peran Serta Kader Hubunganya Dengan Perawatan Hypertensi pada Lansia Di Puskesmas Bangun Tapan Bantul. 2014. Skripsi tidak di Publikasikan.

7. Sarwono, S., Sosiologi Kesehatan, Gadjah Mada University Press, Yogyakarta. 2007.

8. Suwarsono, Analisis peran dan tugas kader posyandu dalam pelaksanaan posyandu lansia di wilayah kerja puskesmas kabupaten temanggung. 2012. Skripsi tidak dipublikasikan

9. Manik. Faktor-faktor yang berhubungan dengan hipertensi pada lansia di posyandu lansia wilayah kerja puskesmas parsoburan kecamatan Siantar Marihat Pematangsiantar. 2011. Skripsi tidak dipublikasikan

10. Atikah, Perilaku Hidup Bersih Dan Sehat, Nuha Medika, Yogyakarta. 2012.

11. Depkes RI Pedoman Pengobatan Dasar Puskesmas Dinkes Propinsi DIY. 2008. 